\title{
Measurement of metabolic turnover in single mouse embryos
}

\author{
R. G. Wales* \\ M.R.C. Unit of Experimental Embryology and Teratology, Carshalton, Surrey SM5 4EF, U.K.
}

\begin{abstract}
Summary. The method for estimation of metabolic turnover by a single embryo at each stage of preimplantation development is based on the incubation of an embryo in the presence of labelled substrate at high specific activity in a miniaturized incubation chamber and the subsequent radioassay of metabolic products. Preliminary tests indicated that the treatment did not affect embryos adversely. Estimates of glycolysis, substrate oxidation and incorporation by mouse embryos throughout the whole of the preimplantation period of development were made. This technique could prove particularly useful for investigating substrate requirements and metabolic turnover in species for which few embryos are available for study.
\end{abstract}

\section{Introduction}

Over the past two decades a considerable body of information on the metabolic turnover of and the pathways operative in preimplantation mammalian embryos has been accumulated. Because of the relative insensitivity of the methods available, large numbers of embryos per replicate were needed for these studies. As a result most of the experiments were performed with mouse embryos which could be collected easily and for which effective methods for in-vitro culture were available. More recently, interest has increased in the culture, transfer and preservation of embryos of other species, including domestic animals and man. In most of these species the small number of embryos that can be collected at any one time has precluded studies of their metabolism and energy substrate needs.

The benefits arising from the development of methods to measure the metabolic turnover of single mammalian embryos would be that (1) the substrate requirements of these embryos could be determined and (2) the technique could be used to determine the viability of developing embryos or to gauge the success of various imposed treatments such as cryopreservation.

In the present experiments, radiochemical techniques (Brinster, 1967; Wales \& Whittingham, 1967) have been adapted to measure the substrate utilization of single mouse embryos throughout the period of preimplantation development.

\section{Materials and Methods}

Collection of embryos. Random-bred albino mice were superovulated by the intraperitoneal injection of 7.5 i.u. PMSG (Intervet Laboratories, Cambridge, U.K.) followed by 7.5 i.u. hCG (Intervet Laboratories) $48 \mathrm{~h}$ later and mated with entire males. Embryos at various stages of preimplantation development were collected by flushing the reproductive tracts of mated animals on successive days after hCG injection. Hepes-buffered medium (Medium M2; Quinn, Barros \& Whittingham, 1982)

"Present address: School of Veterinary Studies, Murdoch University, Murdoch, Western Australia 6150, Australia. 
was used for flushing. In the case of one-cell zygotes, hyaluronidase (hyalurono-glucosaminidase, EC 3.2.1.35: Sigma Chemical Co., St Louis, U.S.A.) was used to remove the cumulus mass and only oocytes with two obvious polar bodies were used in the experiments. In all cases, collected embryos were washed through two samples of bicarbonate-buffered, energy-free medium (Brinster, 1965) before transfer to medium containing the labelled substrate.

Radioisotopes. The energy metabolism of the embryos was studied by following the metabolic fate of $\left[\mathrm{U}-{ }^{14} \mathrm{C}\right] \mathrm{glucose}$ and DL- $\left[1-{ }^{14} \mathrm{C}\right]$ lactate. To increase the sensitivity of the measurements, culture media containing these substrates at high specific activity were prepared. Three different concentrations of glucose were used $(0.28,0.56$ or $5.56 \mathrm{~mm})$. For media containing 0.28 or $0.56 \mathrm{~mm}$-glucose, glucose with high specific activity $(11 \mathrm{GBq} / \mathrm{mmol}$ : Radiochemical Centre, Amersham, U.K.) was used without the addition of unlabelled glucose. Appropriate aliquants of the stock radiochemical were dried in small tubes, and bicarbonate-buffered substrate-free medium was added to give the required concentration of glucose in the medium. When $5.56 \mathrm{~mm}$-glucose was used, culture medium containing unlabelled glucose was added to the aliquant of dried stock isotope to give a final concentration of $5.56 \mathrm{~mm}$-glucose at a specific activity of $1.1 \mathrm{GBq} / \mathrm{mmol}$. For incubations in the presence of $\left[1-{ }^{14} \mathrm{C}\right]$ lactate aliquants of stock isotope were dried and substratefree medium was added to give a concentration of $1.12 \mathrm{~mm}$-lactate at a specific activity of $2 \mathrm{GBq} / \mathrm{mmol}$. After equilibration of the isotopic media with $5 \% \mathrm{CO}_{2}$ in air, small aliquants (5-10 $\mu$ l) were dispensed into oil-filled plastic culture dishes.

Incubation flasks. Embryos were incubated in a small flask constructed from a test tube $12 \mathrm{~mm}$ in diameter and $35 \mathrm{~mm}$ in length, sealed with a gas tight rubber cap. To the inner surface of the side of this flask was bonded a small tapered glass tube to hold the embryo. This was constructed by sealing the end of a drawn Pasteur pipette and was held in place with a glass bond (Loctite (U.K.) Ltd, Welwyn Garden City, U.K.). The diameter of the mouth of this tube was $\sim 1 \mathrm{~mm}$ and its length $\sim 7 \mathrm{~mm}$. On the opposite wall of the incubation flask a second larger tube of $\sim 3 \mathrm{~mm}$ diameter and $\sim 7 \mathrm{~mm}$ length was bonded as a receptacle for sodium hydroxide added at the completion of incubation. A photograph of one of these incubation flasks is shown in Fig. 1.

Before their use, the incubation flasks were thoroughly washed with double glass-distilled water, using a drawn Pasteur pipette to fill and empty the internal chambers. The chambers were then dried by flushing with acetone (AnalaR). This was followed by two washes with $70 \%$ ethanol and irradiation under a u.v. lamp. The flasks were then capped, re-irradiated and stored for use.

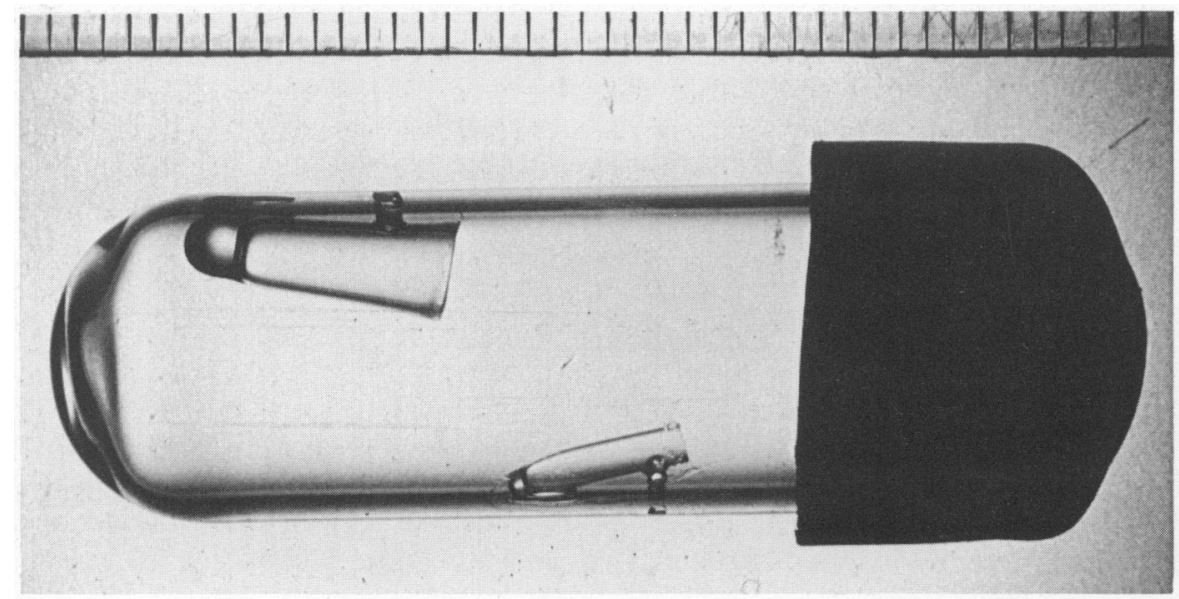

Fig. 1. Photograph of incubation flask showing the small inner tube for holding a single embryo during incubation and the larger receptacle for sodium hydroxide (Scale in $\mathrm{mm}$ ). 
Incubation of embryos. Flasks were prepared by adding a small volume $(\sim 500 \mathrm{nl})$ of sterile low-viscosity paraffin oil to the inner incubation chamber. Embryos were washed individually, transferred with a minimum of medium $(\sim 5-10 \mathrm{nl})$ to a preprepared drop of radioactive medium in a Petri dish, transferred to a second drop of radioactive medium and finally deposited under the oil in the incubation tube in $\sim 500 \mathrm{nl}$ medium. A photograph of the tube after loading is shown in Fig. 2. The tube was then resealed with the rubber cap and gassed for $30 \mathrm{sec}$ with $5 \% \mathrm{CO}_{2}$ in air using 21-gauge hypodermic needles through the rubber cap as inlet and outlet ports. The needles were withdrawn and the flask was placed in an incubator at $37^{\circ} \mathrm{C}$ for $2 \cdot 5 \mathrm{~h}$.

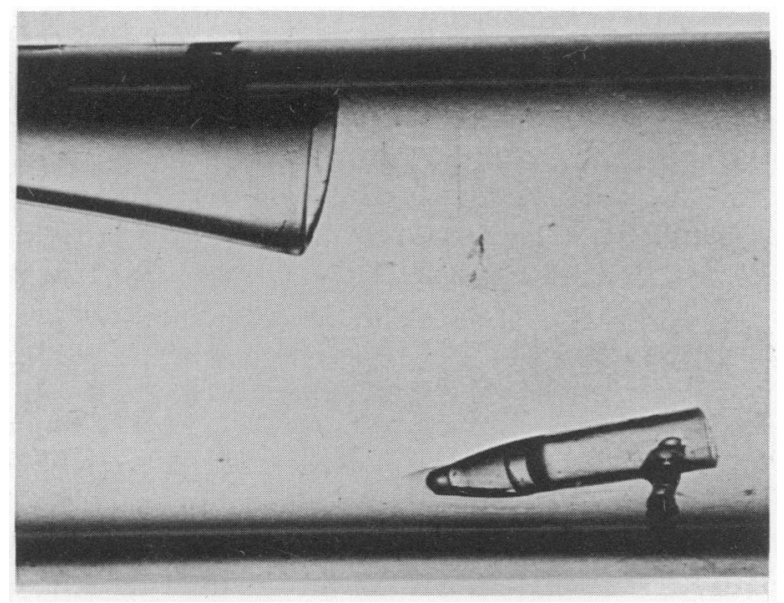

Fig. 2. View of incubation flask after loading small inner tube showing medium $(\sim 500 \mathrm{nl})$ covered by a layer of paraffin oil.

Recovery of $\mathrm{CO}_{2}$ after incubation. At the completion of the incubation metabolism was halted and accumulated $\mathrm{CO}_{2}$ was driven into the atmosphere within the flask by acidifying the incubation medium with $\sim 500 \mathrm{nl}$ phosphate-citrate buffer $\left(\mathrm{pH} \mathrm{3.4)}\right.$. The evolved $\mathrm{CO}_{2}$ was then absorbed into $5 \mathrm{M}$-sodium hydroxide $(\sim 20 \mu \mathrm{l})$ added to the second receptacle within the incubation flask. The acid and alkali were added to the respective receptacles by piercing the rubber cap with the shaft of a 21-gauge hypodermic needle and introducing the buffer or alkali with the aid of a finely drawn Pasteur pipette passed down the shaft of the needle. The flasks were then left at room temperature for $16 \mathrm{~h}$ to ensure complete absorption of $\mathrm{CO}_{2}$ by the alkali.

After equilibration the rubber cap was removed, and the sodium hydroxide was recovered quantitatively. Sodium bicarbonate $(100 \mu \mathrm{l}, 100 \mathrm{~mm})$ was added to the recovered sodium hydroxide as carrier and the absorbed $\mathrm{CO}_{2}$ was precipitated by the addition of $1 \mathrm{ml}$ of $100 \mathrm{~mm}$-barium chloride. The precipitated barium carbonate was recovered on a filter disc, placed in $1 \mathrm{ml}$ of water in a scintillation vial, dispersed by sonication and the radioactivity was assayed after the addition of $10 \mathrm{ml}$ scintillation cocktail. Tests using sodium $\left[{ }^{14} \mathrm{C}\right]$ bicarbonate gave recovery of $>90 \%$ even with amounts of radioactivity as low as 80 d.p.m. As the method of introducing buffer and $\mathrm{NaOH}$ required piercing the cap with a 21-gauge needle for a short space of time, involving possible loss of ${ }^{14} \mathrm{CO}_{2}$ from the flask, this method of adding these components was compared with one using a micrometer syringe and fine-gauge needle of sufficient length to pierce the rubber cap and enter the inner flasks. The recovery of $\mathrm{CO}_{2}$ produced by morulae/early blastocysts using a pipette for additions $\left(2.39 \pm 0.51 \mathrm{pmol} / \mathrm{embryo} \mathrm{h}^{-1} ; n=6\right)$ was not significantly different from recovery using the syringe $\left(2.41 \pm 0.55 \mathrm{pmol} / \mathrm{embryo}^{-1} ; n=6\right)$. 
The efficacy of the acid buffer in driving off all $\mathrm{CO}_{2}$ from the medium was also tested by comparing $\mathrm{CO}_{2}$ recovery using the buffer with recovery when $0.1 \mathrm{M}-\mathrm{H}_{2} \mathrm{SO}_{4}$ was used to acidify the medium. Neither $\mathrm{CO}_{2}$ production nor the amount of glucose carbon incorporated by morulae/early blastocysts was affected by the method of acidifying the medium.

Recovery and assay of medium and embryo. Medium and embryo were quantitatively transferred from the incubation chamber to an oil-filled culture dish. The embryo was picked up in a minimum of medium and washed thoroughly by transfer through at least 4 droplets of isotope-free medium before transfer to a scintillation vial for measurement of radioactivity to assess incorporation of glucose carbon into the embryo during incubation. The volume of the recovered medium was then measured and a small aliquant $(60 \mathrm{nl})$ was assayed for radioaciivity to calculate the original volume of incubation medium used. Over all experiments in this study, the mean volume during incubation was $543 \pm 51 \mathrm{nl}(n=134)$. The remaining medium was frozen at $70^{\circ} \mathrm{C}$ for the assay of lactate production. To quantitate this last parameter, medium was chromatographed for $\sim 16 \mathrm{~h}$ on paper strips using butanol:acetic acid:water $(4: 1: 5 \mathrm{v} / \mathrm{v})$ as solvent. At the completion of chromatography, the strips were cut into $1 \mathrm{~cm}$ segments and each segment assayed for radioactivity. Lactate production was calculated from the net radioactivity found in the peak corresponding to authentic lactate after correction for the recovery of isotope applied to the column.

Assessment of metabolic turnover. The metabolism of glucose was assessed by the recovery of ${ }^{14} \mathrm{CO}_{2}$, the accumulation of $\left[{ }^{14} \mathrm{C}\right]$ lactate in the media and the amount of ${ }^{14} \mathrm{C}$ incorporated into the embryo after incubation and acidification of samples. In all experiments sham incubations were run concurrently to correct for background counts. In the early experiments embryos inactivated by freezing and thawing to $-70^{\circ} \mathrm{C}$ were added to these controls. As the background counts with inactivated embryos did not differ significantly from those obtained with embryo-free controls, the latter were routinely used to correct $\mathrm{CO}_{2}$ and lactate figures. For the incorporation studies, a sample of the last wash before radioassay was used as background. In all cases, radioactivity in the samples was corrected for efficiency of counting and the production of the metabolic product was then calculated from the disintegrations per minute detected in the samples and the specific activity of the parent substrate.

The production of ${ }^{14} \mathrm{CO}_{2}$ from $\left[1-{ }^{14} \mathrm{C}\right]$ lactate was used to assess the rate of entry of this substrate into the citric acid cycle, because the carbon at this position is lost as $\mathrm{CO}_{2}$ in the production of acetyl $\mathrm{CoA}$ for condensation with oxaloacetate to form citrate. The ${ }^{14} \mathrm{CO}_{2}$ evolved was measured using the methods described above for glucose. The embryos were also recovered to determine whether any labelled carbon had been incorporated.

Statistical analysis. The significance of differences was assessed by $t$ tests or analyses of variance as appropriate. Data were transformed to logarithms before analysis to reduce the heterogeneity of variance. When an experiment had unequal observations within cells, the method of unweighted means for disproportionate subclass numbers (Snedecor \& Cochran, 1967) was used in the analysis of variance. If the interaction mean square was significant in the analysis, it was used as error to test the significance of main effects.

\section{Results}

Preliminary experiments were undertaken to appraise the response of embryos to incubation under the conditions used in these studies. In the first experiment the viability of embryos after incubation for $2.5 \mathrm{~h}$ in the flasks was checked. Six samples of $10 \mathrm{embryos}$ at the 2-cell stage were transferred to flasks and incubated $2.5 \mathrm{~h}$ as described in the 'Materials and Methods' before recovery and culture in plastic culture dishes under oil. The development over $72 \mathrm{~h}$ was compared with that of embryos collected at the same time and cultured without previous incubation. Incubation in the flasks had no significant effect on subsequent development. 
At the glucose concentration and specific activity used to measure metabolic activity in these experiments, isotope concentrations as high as $6 \mathrm{MBq} / \mathrm{ml}$ were used. To test the effects of this level of isotope, samples of 2-cell, 8-cell and morula/early blastocyst-stage embryos (300-400/stage) were cultured for $18 \mathrm{~h}$ in media containing [U- $\left.{ }^{14} \mathrm{C}\right]$ glucose $(5.56 \mathrm{~mm})$ at an isotopic concentration of 4.4-6.7 MBq/ml. At the completion of culture, $88-97 \%$ had undergone normal development. In the case of the 8-cell embryos so treated, a small number after recovery ( 2 replicates of 5 embryos each) were cultured a further $48 \mathrm{~h}$ in non-radioactive medium. All developed into expanded blastocysts. Furthermore, it was found that the $\mathrm{CO}_{2}$ produced by morulae/early blastocysts incubated for $25 \mathrm{~h}$ in $5.56 \mathrm{~mm}$-glucose at an isotope concentration of $6 \mathrm{MBq} / \mathrm{ml}\left(5.45 \pm 0.31 \mathrm{pmol} / \mathrm{embryo} \mathrm{h}^{-1}\right.$, $n=3)$ was not different from that produced at a concentration of $0.6 \mathrm{MBq} / \mathrm{ml}(5 \cdot 75 \pm 0 \cdot 10 \mathrm{pmol} /$ embryo $\mathrm{h}^{-1}, n=3$ ).

To test whether the metabolism of single embryos incubated in the flasks remained constant, the metabolism of glucose by Day-4 embryos incubated for 2.5 or $5 \mathrm{~h}$ was compared. The results (Table 1) showed there was no significant difference in the rate of $\mathrm{CO}_{2}$ production, lactate accumulation or substrate incorporation between the two incubation periods used.

Table 1. Rate of oxidation of glucose, conversion to lactate and incorporation by single morulae/early blastocysts during incubation 2.5 or $5.0 \mathrm{~h}$ in the presence of $0.56 \mathrm{~mm}$-glucose

\begin{tabular}{|c|c|c|c|}
\hline $\begin{array}{l}\text { Period of } \\
\text { incubation (h) }\end{array}$ & $\underset{\left(\mathrm{pmol}_{2} / \mathrm{embryo}^{-1}\right)}{\mathrm{CO} \text { produced }}$ & $\begin{array}{l}\text { Lactate produced } \\
\left(\mathrm{pmol} / \mathrm{embryo}^{-1}\right)\end{array}$ & $\begin{array}{l}\text { Glucose incorporated } \\
\text { (pg atoms/embryo } \mathrm{h}^{-1} \text { ) }\end{array}$ \\
\hline $\begin{array}{l}2 \cdot 5 \\
5 \cdot 0\end{array}$ & $\begin{array}{l}1.68 \pm 0.50 \\
1 \cdot 30 \pm 0.63\end{array}$ & $\begin{array}{l}1.90 \pm 0.77 \\
2 \cdot 67 \pm 0.92\end{array}$ & $\begin{array}{l}1 \cdot 17 \pm 0 \cdot 21 \\
1 \cdot 00 \pm 0 \cdot 28\end{array}$ \\
\hline
\end{tabular}

Values are the means \pm s.e.m. for 4 observations.

Embryos were collected on Days 1, 2, 3, 4 and 5 after hCG injection (Day $1=$ day of finding a copulatory plug) and incubated $2.5 \mathrm{~h}$ in $0.25,0.56$ or $5.56 \mathrm{~mm}-\left[\mathrm{U}-{ }^{14} \mathrm{C}\right] \mathrm{glucose}$ as described in the 'Materials and Methods'. Cumulus-free, unfertilized oocytes flushed from unmated females $\sim 18 \mathrm{~h}$ after hCG injection were also included in the study. A summary of the results of $\mathrm{CO}_{2}$ production, substrate incorporation and lactate production by these embryos is given in Table 2 . Analysis of the data for $\mathrm{CO}_{2}$ production gave highly significant effects of stage of development and glucose concentration $(P<0.01)$ but no interaction between these factors. The zygote produced more $\mathrm{CO}_{2}$ than did the unfertilized ovum $(P<0.01)$ and there was a curvilinear increase in this indicator of metabolism with development. Embryos incubated in $5.56 \mathrm{~mm}$-glucose converted more glucose to $\mathrm{CO}_{2}$ than did those in $0.56 \mathrm{~mm}$-glucose. Unfertilized oocytes incorporated virtually no glucose. Statistical analyses of the remaining data on incorporation revealed a significant interaction between glucose concentration and stage of development. Using this interaction as error, there was a significant linear increase in incorporation with development $(P<0.01)$ and an increase in incorporation with increasing glucose concentration $(P<0.05)$. For the production of lactate, only the data between Days 3 and 5 were included in the analysis because production by 1 -cell embryos was close to zero. Again there was a linear increase in production with development $(P<0.01)$ and a similar response to changing glucose concentration $(P<0.01)$ as seen for the other indicators. There was no evidence of interaction in this analysis.

Inspection of the data in Table 2 showed there was a sharp increase in variability on Day 4. To test whether this was due to asynchrony of development at this stage, embryos on Day 4 were separated into morulae and early blastocysts before culture. The results using 4 embryos in each group showed that the $\mathrm{CO}_{2}$ and lactate production by blastocysts from $0.56 \mathrm{~mm}$-glucose was at least twice that by morulae $\left(2.06 \pm 0.51\right.$ vs $0.86 \pm 0.21 \mathrm{pmol} \mathrm{CO}_{2} / \mathrm{embryo} \mathrm{h}^{-1}$ and $3.25 \pm 0.89$ vs $1.33 \pm 0.33$ lactate/embryo $\mathrm{h}^{-1}$ respectively) whilst incorporation was $50 \%$ higher $(1.33 \pm 0.27 v s$ $0.84 \pm 0 \cdot 11 \mathrm{pg}$ atoms/embryo $\mathrm{h}^{-1}$ ). 
Table 2. Metabolic indicators of single mouse embryos cultured for $2.5 \mathrm{~h}$ in microincubation chambers

\begin{tabular}{|c|c|c|c|}
\hline \multirow{2}{*}{$\begin{array}{l}\text { Stage of } \\
\text { development }\end{array}$} & \multicolumn{3}{|c|}{ Glucose conc. in medium (mM) } \\
\hline & $0 \cdot 28$ & 0.56 & $5 \cdot 56$ \\
\hline \multicolumn{4}{|c|}{$\mathrm{CO}_{2}$ production (pmol/embryo $h^{-1}$ ) } \\
\hline \multicolumn{4}{|c|}{ 1-cell } \\
\hline Unfertilized & $0.11 \pm 0.07(2)$ & $0.08 \pm 0.01(2)$ & $0 \cdot 19 \pm 0 \cdot 04(2)$ \\
\hline Fertilized & $0.19 \pm 0.05(3)$ & $0 \cdot 46 \pm 0.15(5)$ & $1 \cdot 38 \pm 0 \cdot 16(7)$ \\
\hline 2-cell & $0.29 \pm 0.01(2)$ & $0.37 \pm 0.07(4)$ & $0.67 \pm 0.21(4)$ \\
\hline 8-cell & $0.34 \pm 0.10(4)$ & $0.51 \pm 0.08(4)$ & $1 \cdot 23 \pm 0.39(4)$ \\
\hline \multicolumn{4}{|l|}{ Morula/early } \\
\hline blastocyst & $1.95 \pm 0.24(13)$ & $2.95 \pm 0.45(\mathrm{I} 2)$ & $3.54 \pm 0.59(9)$ \\
\hline Late blastocyst & $2 \cdot 15 \pm 0 \cdot 17(7)$ & $2 \cdot 59 \pm 0 \cdot 24(6)$ & $3 \cdot 21 \pm 0 \cdot 54(7)$ \\
\hline \multicolumn{4}{|c|}{ Incorporation of glucose ( $p g$ atoms/embryo $h^{-1}$ ) } \\
\hline \multicolumn{4}{|l|}{ 1-cell } \\
\hline Unfertilized & $0.00(1)$ & $0.00 \pm 0.05(2)$ & $0.05 \pm 0.05(2)$ \\
\hline Fertilized & $0.03 \pm 0.02(3)$ & $0.05 \pm 0.04(5)$ & $0.42 \pm 0.12(7)$ \\
\hline 2-cell & $0.03 \pm 0.01(2)$ & $0 \cdot 70 \pm 0 \cdot 36(4)$ & $0.57 \pm 0.25(4)$ \\
\hline 8-cell & $0.25 \pm 0.09(4)$ & $0 \cdot 34 \pm 0 \cdot 10(6)$ & $0.66(1)$ \\
\hline \multicolumn{4}{|l|}{ Morula/early } \\
\hline blastocyst & $0 \cdot 85 \pm 0 \cdot 15(8)$ & $1.49 \pm 0 \cdot 14(15)$ & $1.45 \pm 0 \cdot 16(7)$ \\
\hline Late blastocyst & $1.89 \pm 0.42(8)$ & $1 \cdot 56 \pm 0 \cdot 22(8)$ & $1 \cdot 90 \pm 0 \cdot 30(8)$ \\
\hline \multicolumn{4}{|c|}{ Lactate production (pmol/embryo $h^{-1}$ ) } \\
\hline \multicolumn{4}{|c|}{ 1-cell } \\
\hline Fertilized & $0 \cdot 04 \pm 0.03(2)$ & $0.05 \pm 0.05(2)$ & $0.00(2)$ \\
\hline 8-cell & $0.03(1)$ & $0.08 \pm 0.02(4)$ & $0.60 \pm 0.04(2)$ \\
\hline \multicolumn{4}{|l|}{ Morula/early } \\
\hline blastocyst & $0.68 \pm 0.32(7)$ & $1 \cdot 64 \pm 0.44(8)$ & $1 \cdot 78 \pm 0.56(4)$ \\
\hline Late blastocyst & $1.78 \pm 0.31(2)$ & $2.07 \pm 0.53(2)$ & $3 \cdot 47 \pm 1.32(2)$ \\
\hline
\end{tabular}

Values are the means \pm s.e.m. (no. of observations).

The need to maximize the sensitivity of the assay and to use adequate controls is illustrated by the comparison of radioactivity counts recovered from incubated embryos with those from controls (Table 3). On the day of fertilization, counts from embryos were never more than double those of controls, even at the higher specific activity. When the lower specific activity of $1 \cdot 1 \mathrm{GBq} / \mathrm{mmol}$ was used, counts only reached twice that of the background at the morula/early blastocyst stage. To confirm that estimates on single embryos under these conditions were valid, the metabolic turnover estimated on single embryos was compared with that of embryos from the same collection assessed as groups of $2-5$. For morulae/early blastocysts incubated in $0.56 \mathrm{mM}$-glucose there was no significant difference in $\mathrm{CO}_{2}$ production $\left(t_{4}=1 \cdot 48\right)$, incorporation $\left(t_{4}=0.33\right)$ or lactate production

Table 3. Mean uncorrected counts (cpm) recovered in ${ }^{14} \mathrm{CO}_{2}$ and ${ }^{14} \mathrm{C}$ incorporated by embryos incubated for $2.5 \mathrm{~h}$ in $\left[\mathrm{U}^{-14} \mathrm{C}\right]$ glucose as compared to control values

\begin{tabular}{lccccc}
\hline & \multicolumn{2}{c}{ Counts in ${ }^{14} \mathrm{CO}_{2}$ at: } & & \multicolumn{2}{c}{ Counts incorporated at: } \\
\cline { 2 - 3 } \cline { 6 - 6 } Stage of development & $11 \mathrm{GBq} / \mathrm{mmol}$ & $1 \cdot 1 \mathrm{GBq} / \mathrm{mmol}$ & & $11 \mathrm{GBq} / \mathrm{mmol}$ & $1 \cdot 1 \mathrm{GBq} / \mathrm{mmol}$ \\
\hline Unfertilized & 68 & 51 & & 26 & 27 \\
Zygotes & 115 & 87 & & 32 & 31 \\
Morula/early blastocyst & 513 & 116 & & 261 & 57 \\
Controls & 50 & 49 & & 24 & 24 \\
\hline
\end{tabular}


Table 4. Comparison of the metabolic turnover of mouse embryos incubated in the presence of 5.56 or $0.56 \mathrm{~mm}$-glucose either singly or in groups

\begin{tabular}{|c|c|c|c|c|c|}
\hline \multirow{2}{*}{$\begin{array}{l}\text { Stage of } \\
\text { development }\end{array}$} & \multirow{2}{*}{$\begin{array}{l}\text { Condition of } \\
\text { incubation }\end{array}$} & \multicolumn{2}{|c|}{$\begin{array}{c}\mathrm{CO}_{2} \text { production } \\
\left(\mathrm{pmol} / \mathrm{embryo}^{-1}\right)\end{array}$} & \multicolumn{2}{|c|}{$\begin{array}{c}\text { Incorporation } \\
\left(\text { pg atoms } / \text { embryo }^{-1}\right)\end{array}$} \\
\hline & & $5.56 \mathrm{~mm}$ & $0.56 \mathrm{mM}$ & $5.56 \mathrm{mM}$ & $0.56 \mathrm{mM}$ \\
\hline \multirow[t]{2}{*}{ Unfertilized } & Singly & $0.19 \pm 0.04(2)$ & - & $0 \cdot 0(2)$ & - \\
\hline & Group of 2 & $0.21 \pm 0.03(2)$ & - & $0.0(2)$ & - \\
\hline \multirow[t]{2}{*}{ 2-cell } & Singly & $0.32 \pm 0.05(2)$ & $0.37 \pm 0.07(4)$ & $1.00 \pm 0.03(2)$ & $0 \cdot 70 \pm 0.36(4)$ \\
\hline & Group of 5 & $0.38 \pm 0 \cdot 10(2)$ & $0.41 \pm 0.03(3)$ & $1 \cdot 33 \pm 0 \cdot 20(2)$ & $0.67 \pm 0.36(4)$ \\
\hline
\end{tabular}

Values are the mean \pm s.e.m. (no. of observations).

Table 5. Decarboxylation of lactate by single mouse embryos cultured for $2.5 \mathrm{~h}$ in micro-incubation chambers

\begin{tabular}{lc}
\hline Stage of development & $\begin{array}{c}\mathrm{CO}_{2} \text { released from carbon 1 position } \\
\left(\mathrm{pmol} / \mathrm{embryo}^{-1}\right)\end{array}$ \\
\hline 1-cell & $0 \cdot 62 \pm 0.03(3)$ \\
Unfertilized & $0 \cdot 54 \pm 0 \cdot 16(3)$ \\
Fertilized & $0.57 \pm 0.03(2)$ \\
2-cell & $0 \cdot 58 \pm 0.01(2)$ \\
8-cell & $0 \cdot 80 \pm 0.03(3)$ \\
Morula/early blastocyst & $0 \cdot 87 \pm 0.05(2)$ \\
Late blastocyst & \\
\hline
\end{tabular}

Values are the means \pm s.e.m. (no. of observations).

$\left(t_{3}=0.87\right.$ ) between estimates on single embryos and those on groups. Tests were also undertaken with unfertilized oocytes and 2-cell embryos and the results are given in Table 4. Both means and standard errors of estimates of metabolic turnover for embryos incubated individually were similar to those for estimates based on groups of embryos.

Finally, the rate of carbon dioxide production from $\left[1-{ }^{14} \mathrm{C}\right]$ lactate was measured at each stage of development (Table 5). Significant amounts of lactate were decarboxylated by the unfertilized oocyte. No change occurred with fertilization or during early cleavage but the values from morula formation onwards were significantly elevated. No isotope was incorporated into embryos incubated in $\left[1-{ }^{14} \mathrm{C}\right]$ lactate.

\section{Discussion}

The present experiments amply demonstrate that estimates of glycolysis, oxidative utilization of glucose and the intracellular incorporation of this substrate can be made on single mouse embryos at all stages of preimplantation development.

To accomplish this, embryos had to be incubated in small volumes in the presence of high concentrations of isotope under somewhat unusual culture conditions. However, preliminary experiments failed to demonstrate overt deleterious effects of these conditions on embryos. For example, the rate of $\mathrm{CO}_{2}$ production per embryo was constant for at least $5 \mathrm{~h}$ and was unaffected by the number of embryos per flask. Subsequent viability was unaffected by the $2.5 \mathrm{~h}$ sojourn in the flasks, and the presence of the high levels of isotope, even for $24 \mathrm{~h}$, did not reduce the capacity for normal development. Furthermore, a 10 -fold change in specific activity at constant glucose concentrations did not affect the estimate of glucose oxidation. Therefore, the results obtained under these conditions should represent reliable estimates of metabolic turnover in viable embryos. 
Even with the high specific activity of isotope used in the present studies, recovery of label in metabolic products and in embryos was low, ranging from just above background to levels never more than 10 times this figure. Therefore, when using these isotopic methods to measure the metabolism of single embryos special attention to minimizing background counts and including adequate controls to estimate backgrounds accurately is necessary. The somewhat tedious procedure of barium carbonate precipitation and washing of absorbed carbon dioxide was justified as on some occasions the washings contain small amounts of soluble label which would have led to an overestimate of $\mathrm{CO}_{2}$ production had direct counts been made.

The results of the study at various developmental stages indicated that a significant change in glucose utilization occurs with fertilization, followed by an increasing utilization of the substrate for catabolic and anabolic purposes as development progresses. Furthermore, the relative constancy of the decarboxylation of $\left[1-{ }^{14} \mathrm{C}\right]$ lactate during early development points to adequate TCA cycle activity and indicates that the early lack of glucose utilization is due to a blockade to glycolysis, a situation adequately demonstrated in other studies (Barbehenn, Wales \& Lowry, 1978).

The trends in glucose oxidation found here are similar to those reported by Brinster (1967) using groups of embryos. However, the values at the later stages of preimplantation development are only $20-30 \%$ of those found in this earlier work. The extensive checks on the methods used in the present study failed to indicate a technical problem that might explain this discrepancy. The significant differences in estimates between the studies would therefore seem to be genuine rather than artefacts of the methodology. Reports from different laboratories (Menke \& McLaren, 1970; Menke, 1972; Torbet \& Weitlauf, 1974, 1975) indicate considerable variability between estimates of glucose oxidation at the later stages of preimplantation development in the mouse. Such results point to possible differences between strains in the ability to metabolize this substrate.

The estimates of lactate production gave similar trends with development to those reported earlier (Wales, 1969) but the values were also considerably lower. By combining the present data for $\mathrm{CO}_{2}$ and lactate production, an estimate of the amount of glucose utilized that is oxidized can be made. The values, $70 \%$ at the 1-cell stage falling to $30 \%$ at the late blastocyst stage, are similar to those calculated by Wales (1969) for the earlier studies and further support the suggestion that strain differences in the utilization of this substrate by mouse embryos may exist.

It is difficult to speculate on the possible identity of the labelled compounds remaining in the embryo after acidification and storage for $16 \mathrm{~h}$. Glucose carbon incorporated into more labile and diffusible intracellular pools should be lost when the integrity of the cell membranes is disrupted by the above treatment and the embryos are extracted in mild acid overnight. Nevertheless, the changes in residual incorporation during development follow a pattern similar to those found for incorporation into the non-glycogen, acid-insoluble fraction in earlier studies (Edirisinghe, Wales \& Pike, 1984). This fraction contains most of the macromolecules, other than glycogen, that are synthesized during incubation. The incorporation measured in the present studies would therefore appear to be a useful index of anabolic utilization of the substrate by the embryo when the limited availability of embryos precludes more precise measurements.

The present study has shown that, using a single embryo, it is possible to make meaningful estimates both of catabolic and anabolic metabolism at all stages of development before implantation. Such methods should have considerable potential as a tool for assessing the metabolic turnover and perhaps the viability of embryos in animals of species for which it is difficult to obtain more than a few embryos for study.

I thank Dr D. G. Whittingham and the Medical Research Council for the provision of laboratory facilities; Ms K. Hardy and Mr J. Hunter for technical assistance; the Royal Society and Nuffield Foundation for financial support; and Murdoch University for the support of this Outside Studies Programme. 


\section{References}

Barbehenn, E.K., Wales, R.G. \& Lowry (1978) Measurement of metabolites in single preimplantation mouse embryos: a new means to study metabolic control in early embryos. J. Embryol. exp. Morph. 43, 29-46.

Brinster, R.L. (1965) Studies of the development of mouse embryos in vitro. II The effect of energy source. J. exp. Zool. 158, 59-68.

Brinster, R.L. (1967) Carbon dioxide production from glucose by the preimplantation mouse embryo. Expl Cell. Res. 47, 271-277.

Edirisinghe, W.R., Wales, R.G. \& Pike, I.L. (1984) Synthesis and degradation of labelled glycogen pools in preimplantation mouse embryos during short periods of in vitro culture. Aust. J. biol. Sci. 37, 137-146.

Menke, T.M. (1972) Changes in mouse blastocyst carbon dioxide production as a function of time postcoitum in delay of implantation during lactation or following ovariectomy. Biol. Reprod. 7, 414-416.

Menke, T.M. \& McLaren (1970) Carbon dioxide production by mouse blastocysts during lactational delay of implantation or after ovariectomy. J. Endocr. 47, 287-294.
Quinn, P., Barros, C. \& Whittingham, D.G. (1982) Preservation of hamster oocytes to assay the fertilizing capacity of human spermatozoa. J. Reprod. Fert. 66, 161-168.

Snedecor, G.W. \& Cochran, W.G. (1967) Statistical Methods, 6th edn. The Iowa State University Press, Ames, Iowa.

Torbet, C.A. \& Weitlauf, H.M. (1974) The effect of oestrogen and progesterone on $\mathrm{CO}_{2}$ production by delayed implanting mouse embryos. J. Reprod. Fert. 39, 379-382.

Torbet, C. A. \& Weitlauf, H.M. (1975) Production of carbon dioxide in vitro by blastocysts from intact and ovariectomised mice. J. Reprod. Fert. 42, 45-50.

Wales, R.G. (1969) Accumulation of carboxylic acids from glucose by the pre-implantation mouse embryo. Aust. J. biol. Sci. 22, 701-707.

Wales, R.G. \& Whittingham, D.G. (1967) A comparison of the uptake and utilization of lactate and pyruvate by one- and two-cell mouse embryos. Biochem. Biophys. Acta 148, 703-712.

Received 27 July 1985 